Для специалистов ее труд, к сожалению, представляет ничтожно малый интерес, так как автору свойственны, во-первых, некорректная работа с источниками, во-вторых, нелогичность построений, в-третьих, плохое знание историографии борисоглебской темы и, в-четвертых, умолчание данных источников и мнений ученых, противоречащих ее построениям. Книга не дает верифицируемых ответов ни на один из серьезных вопросов, которые стоят перед исследователями борисоглебской темы. ${ }^{25}$

Простой читатель, купив этот том, приобретет переиздание недавно вышедшего перевода Сказ., а также впервые выполненный перевод двух памятников борисоглебского цикла (Чтен. и паримийных чтений), которому предпослано огромное хаотично выстроенное наукообразное введение.

С. М. Михеев

\title{
А. Г. ХРушковА, Раннехристианские памятники Восточ- ного Причерноморья (М.: Наука, 2002) 500 с., LXXX Табл.
}

Давнее знакомство с Л. Г. Хрушковой но, к сожалению, редкие встречи, во время которых разговор завязывается не только о научных идеях, но и о сложностях современной жизни, трудностях издания обобщающих публикаций, доверительность отношений, которая сопровождает все наши беседы, не позволяют создать просто рецензию, в которой бы были отражены, как принято, достоинства и недостатки новой книги. Кому как не автору, который многие годы жил и работал в Абхазии, великолепно знает ее памятники, не однократно выступал и с докладами, популярными очерками, ${ }^{1}$ посвятил ряд монографических работ некоторым видам археологических источников, ${ }^{2}$ или же обобщил раскопки отдельных, ${ }^{3}$ чрезвычайно сложных в исследовании памятников, ясно

${ }^{25}$ К чести Н. И. Милютенко, в книге полностью отсутствуют разделы, где она подводила бы итоги своей работы.

${ }^{1}$ В данном случае мне хотелось бы назвать только одно небольшое по объему монографическое исследование, написанное настолько легким стилем, не принятым в те годы в научных изданиях, что его можно считать и научно-популярной работой: Л. Г. ХрушковА, Цандрипш: Материалы по раннехристианскому строительству в Абхазии (Сухуми, 1985).

2 Л. Г. ХрушковА, Скульптура раннесредневековой Абхазии: V-X века (Тбилиси, 1980).

3 Л. Г. ХрушковА, Лыхны: Средневековый дворцовый комплекс в Абхазии (M., 1998). 
то, что осталось не до конца продуманным. А спустя годы, которые отделяют начало изучения того или иного памятника, увидеть поспешность раскопок, диктуемую чаще всего объективными причинами, логическую незавершенность исследования. В данном случае мне хотелось бы лишь представить читателю новую книгу Л. Г. Хрушковой.

Но начну я не с монографии.

В последние годы в нашей стране, после значительного перерыва, появляется интерес к христианской археологии. Об этом свидетельствует серия статей, опубликованных в различных изданиях, в которых рассматриваются общее и отличное между византийской и христианской археологией и отмечено, обсуждаются вопросы городской и христианской топографии. Закономерно, что автором многих из них является Л. Г. Хрушкова, изучившая не только памятники Грузии и Абхазии, но и Крыма, Италии, читавшая лекции по византийской археологии в Париже. ${ }^{4}$

Христианская топография - это не только выявление места культовых сооружений в системе городской застройки, но и литургическое назначение частей храма, ${ }^{5}$ что для светского специалиста является чрез-

${ }^{4}$ Например, см.: Л. Г. ХрушковА, Христианская археология в Восточном Причерноморье // ПС 32 (95) (1993); Л. Г. ХрушковА, Христианская археология в Западной Европе и русская школа византинистики // Ученые Записки Росссийского Православного университета 5 (2000); Л. Г. ХРушковА, О византийской археологии // Вестник РГНФ (2001) № 3; Л. Г. ХрушковА, Археология христианская, византийская, церковная: термины, предмет, современное состояние // Точки (2001) № 3-4.

${ }^{5}$ Примечательным является вопрос, который поставлен в настоящей монографии «Христианская или византийская археология?», в преамбуле которого Л. Г. Хрушкова сразу же определяет свое отношение: «Восточное Причерноморье, как и Крым, равным образом принадлежат двум ветвям исторического знания: христианской археологии и археологии византийской». Говоря о связи этих «двух ветвей исторического знания», она отмечает, что византийская археология, не будучи долгое время самостоятельной отраслью науки, «отделилась» от христианской археологии (с. 32). Безусловно, каждый из нас имеет право на собственное мнение, но, если анализировать историю раскопок различных центров, как Восточного Причерноморья, так и Таврики, то, пожалуй, более справедливым является заключение, что византийская археология «не отделилась», а развивается на основе тех достижений, которые были выработаны нашими предшественниками в области античной археологии. Вместе с тем автор совершенно права, в том, что «только в последние десятилетия она (византийская археология. - А. Р.) нашла (или, может быть, еще только находит) свой дисциплинарный статус как особая отрасль исторического знания. К мнению Е. ZANINI (Introduzione all' archeologia byzantina (Roma, 1994) (Studi Superiori, n.s. 228, Archeologia) 11) можно добавить мнения и других авторов, которые неоднократно писали о поиски стратегии и тактике византийской археологии (J. H. RoseR, 
вычайно сложной темой, ${ }^{6}$ так как это требует не только знаний особенностей христианского ритуала, и умения сопоставить их, а также свидетельств житийной литературы с открытыми в процессе раскопок памятниками. Все эти качества и проявились в новой работе, представить которую, как уже было сказано, но не писать о ее достоинствах и недостатках, мне хотелось бы в данном случае.

Итак, какие проблемы обсуждает Л. Г. Хрушкова со своими читателями, доказательству каких вопросов посвящена чрезвычайно фундированная монография.

Ответ на эти вопросы содержится в самом содержании исследования, в кратких резюме, сопровождающих каждую главу.

Центральное место и большую часть страниц, что является закономерным, посвящено непосредственному описанию культовых памятников рассматриваемого региона, о местоположении которых позволяет получить карта (с. 8).

Некоторые из них давно известны и к ним неоднократно обращались исследователи. Это прежде всего трехапсидная крестовидная церковь в Питиунте (№ 7 по нумерации Л. Г. Хрушковой). Этот памятник, имевший долгую историю и неоднократные перестройки, пожалуй, известен любому посетителю данного курортного центра ${ }^{7}$. Но от глаз посетителей, подчас и исследователей скрыты другие не менее интересные комплексы, которые позволяют решать вопросы топографии Питиунта и его роль в культурной и религиозной жизни Восточного Причерноморья. Обобщая работы своих предшественников, автор делает вывод о том, что «небольшая христианская община города уже в IV-V вв. возводит первый храм. Последовательное строительство на том месте, где возник храм IV-V вв. (судя по описанию сменявших друг друга построек,

A Reserch Strategy for Byzantine Archaeology // Byzantine Studies 6 (1979) 152-166) или о том, что она все еще находится в эмбриональном состоянии (Е. KISLINGER, Notizen zur Realienkunde aus byzantinischer Sucht // Medium Aevum Quotidianum 9 (1987) 33; cp.: E. KISLINGER, La cultura materiale di Bisanzio. Un nuovo inizio della ricerca scientifica // Schede Medievali 11 (1986) 299-313). Важнейшими связующими античную и византийскую археологию, на мой взгляд, являются проблема культурного слоя и методика раскопок архитектурных памятников, которые имеют многовековую историю.

${ }^{6}$ Л. Г. ХРушковА, Новая октогональная церковь в Севастополисе и ее литургическое устройство // Литургия, архитектура и искусство византийского мира: Труды XVIII Международного конгресса византинистов (Москва, 8-15 августа 1991) и другие материалы, посвященные памяти о. Иоанна Мейендорфа / Под редакцией К. К. АкЕнтьЕВА (СПб., 1995) (Византинороссика 1) 201-235.

${ }^{7}$ Церковь № 7 датируется второй половиной VI или началом VII в. По мнению автора, строительство ее связано с возрождением Питиунта после разрушения 542 г. (с. 109). 
Л. Г. Хрушкова склоняется к более ранней дате), завершается сооружением однонефной церкви в начале VI в. (храм № 4, с. 91).

Следующий значительный комплекс культовых сооружений Апсилии - памятники в расположенном к северо-западу от Питиунта, неподалеку от г. Гагры, с. Алахазды. К числу наиболее ранних относится трехнефная базилика (№ 1 по Л. Г. Хрушковой). Открытая еще П. С. Уваровой (1886 г.) она, в сущности, в течение ста лет (до раскопок 1985-1986 г.) оставалась не исследованной. Раскопки автора монографии позволили выявить сложную строительную биографию здания, открыть три последовательно возводимых храма, восстановить план сооружений, отчасти архитектурное убранство, но, к сожалению, определить время первой, самой ранней постройки, не удалось. На основании аналогий и использования техники opus mixtum ${ }^{8}$ она датируется V в. (c. 123, 127). Вторая базилика возводится в конце VIII - первой половине IX в., позднее рядом с ней возникает храм № 3. Раскопки позволили проследить эволюцию культового строительства в одном из значительных центров Пицундского мыса - от стропильной базилики к купольному храму. Интерес представляет и вывод о влиянии первого этапа строительной деятельности в населенном пункте, существовавшем ранее на месте с. Алахазды, на детально исследованную Л. Г. Хрушковой Цандрипшскую базилику (c. 135). И закономерно, что следующая глава посвящена именно ей.

Итак, глава 3 «Цандрипшская базилика и другие памятники Абазгии» (с. 137-194).

Безусловно, наибольшее внимание уделено именно базилике, тем деталям, которые были обнаружены в процессе раскопок автора: периодизация строительства, планировка и структура храма (баптистерий, мемориальная крещальня, функции трехапсидного алтаря, типология гробниц, вписанных, как отмечено, «в интерьер базилики». Тщательному анализу подвергнуты немногочисленные строительные материалы и конструкции, и многочисленные мраморные детали, сохранившиеся надписи (с. 160-163, 165-170). Перечисленные выше сюжеты, а также археологические находки ${ }^{9}$ склоняют Л. Г. Хрушкову к выводу о том, что в

${ }^{8}$ Правда, Л. Г. Хрушкова отмечает, что это косвенный признак (с. 127).

${ }^{9}$ Среди археологических находок (амфоры и стеклянные сосуды) на перовом месте и более подробно описываются амфоры со ссылкой на широкую датировку, предложенную А. В. Сазановым (с. 171, прим. 101). В отношении так наз. амфор «с перехватом» (вернее, с сужением корпуса) хотелось бы отметить, что в Херсонесе они встречаются в хорошо датированных комплексах VI в. и в слоях разрушения, датированных монетами VII в. (см.: А. И. РомАнчук, А. В. САзАнов, Л. В. СЕдиковА, Амфоры из комплексов византийского Херсона (Екатеринбург, 1995) 16-19). Для Л. Г. Хрушковой есть и более близкая хронологическая аналогия таких амфор - находки в храме Дранда (см.: М. К. ХотЕЛАшвили, А. Л. ЯкоБСон, Византийский храм в с. Дранда (Абхазия) // BB 45 (1984) 192-206), описание 
VI в. строится (с. 151) «первая церковь абазгов», судя по обнаруженной надписи, в которой они названы.

Из других храмов данной главы описаны: однонефная церковь VI в., расположенная в крепости в ущелье Хашупса; не изученная до настоящего времени «трехцерковная базилика» в г. Гагры (рубеж V-VI или первые десятилетия VI в.); храм VII-VIII вв. в местечке Аба-Анта (около с. Лыхны); приведены также соображения о существовании храма в таком важнейшем центре Абазгии как Анакопия (с. 191-194).

Особый интерес представляет раздел о памятниках приморских центров (читатель может видеть, что это сочетание «особый интерес» с различными оттенками уже неоднократно использован и свидетельствует о том, что каждая из глав, имеющая «центральное ядро», сообщающая или совершенно новые данные, или обобщающая и анализирующая ранее полученные материалы, по своему примечательна и, конечно, ценна). В главе 4 таким ядром стал подробно разобранный культовый комплекс Севастополиса, одного из крупнейших городов Колхиды (с. 195259). Многочисленные рисунки и чертежи стратиграфических разрезов, а также находки позволили восстановить строительную биографию памятника и отнести его строительства ко времени ранее середины VI в. (c. 240), возможно, даже к началу V в. (с. 250).

Следующий храм в главе 4 «Севастополис и другие приморские центры» - это купольная церковь в с. Дранда, расположенном в 23 км от Сухума. Непрерывное существование храма вплоть до конца XIX в., неоднократные «подновления» затруднили его изучение и породили дискуссию о типе здания и времени строительства (с. 265-270). Одна из ранних датировок принадлежит Г. Н. Чубинашвили, который счел возможным включить церковь в «группу памятников “типа Джвари”» (VIII в.). Другие грузинские исследователи, отметив «в строительной технике византийские черты» датировали постройку в Дранде переходным периодом - VIII-IX вв. Не буду перечислять все точки зрения, приве-

которой и дискуссия о датировке содержатся в следующей главе (с. 259-273). Кроме того, на рис. 55 (с. 171) изображена еще одна амфора с бороздчатым в верхней части корпусом, в средней и нижней - с редкими валиками (безусловно, небольшой размер рисунка не дает о ней полного представления). Данные амфоры имеют более узкую датировку (А. И. РомАнчук, Очерки истории и археологии византийского Херсона (Екатеринбург, 2000) 171-173, рис. 71). Хотелось бы обратить внимание на изображение плинфы (с. 178, рис. 58), которая, судя по материалам и Херсонеса и раскопкам памятников на территории Болгарии, уже не производилась в VII в. (см.: С. АнгеловА, За производство на строителна керамика в Североизточна България през ранното средновековие // Археология (1971) № 3. C. 3-24), в которой обобщены все виды находок с IV-VI вв. до Х в. Плинфа с хаотически нанесенными знаками в виде полос, овалов, зигзагообразных линий, как отмечает исследовательница, встречается в постройках вплоть до VI в.) 
денные Л. Г. Хрушковой (с. 266-268), которая считает, что более близки в выявлении времени возведения храма М. К. Хотелашвили и А. Л. Якобсон (вторая половина VI в.), но на основании не замеченных ими деталей делает уточнение: «самая вероятная дата памятника VII в.» (с. 270).

Третий из храмов черноморского побережья - это однонефная кладбищенская церковь на городище Гиенос (с. 273-290), первый строительный период которой относится ко второй половине $\mathrm{V}$ в., а разрушение ее к VII в. (с. 290).

В отличие от упомянутых храмов, в той или иной мере известных по многочисленным публикациям (в том числе и российских научных изданиях), памятникам нагорной Апсилии (глава 5) должного внимания не уделялось, хотя и относительно Цебельдинской долины, где они расположены, благодаря прежде всего раскопкам Ю. Н. Воронова имеется достаточно хорошее представление. (Правда, вряд ли о каком-либо регионе, или памятники с полным правом мы можем сказать, что существует «достаточно хорошее представление».) Значение данной главы состоит не только в том, что здесь представлены данные собственных раскопок, но и обобщены разрозненные по различным изданиям материалы. Это позволяет получить представление о культовой архитектуре района: комплекс в крепости Цибила (две раннехристианские, одна позднесредневековая церковь - XIII-XIV вв. (с. 295), но существующая вплоть до начала XVIII в. (с. 298).

Далее, в главе приведены планы и краткое описание церкви в крепости Шапкы (раскопки не завершены), однонефного храма VI в. в с. Мрамба и сообщается о значительной серии рельефной скульптуры местных мастеров, что требует, как отмечает автор, специального анализа и хронологически «выходит за пределы темы».

Последний регион, которому посвящена глава 6 «Памятники Южной Лазики», является обобщением исследований, проведенных в различные годы грузинскими археологами и архитекторами. Отсутствие ссылок на собственные работы, что, безусловно, не означает отсутствия своего мнения относительно интерпретации и хронологии открытых здесь комплексов, все же позволяет судить о вторичности анализируемой информации, поэтому считаю возможным ограничиться только перечислением находящихся, вернее, раскопанных здесь памятников.

Перечислю их, согласно содержанию: Зиганис (Гудава) - баптистерий, возможно, V в.; Археополис (Нокалакеви) - открыто несколько церквей за пределами городской территории (важнейшим результатом, по мнению, Л. Г. Хрушковой, является обнаружение в столице Лазики храмов IV-VI вв., ${ }^{10}$ что кардинально меняет мнение о ранней христиа-

${ }^{10}$ O раннем храме, отнеся возведение его к IV в., писал в 1991 г. Н. Ю. Ломоури, отметивший, что после разрушения над развалинами сооружается большая 
низации населения (ранее этот процесс относили к VI в. (с. 334). Автор монографии отмечает, что культовое строительство в Археополисе «имеет много общего с Питиунтом, который во второй четверти IV в. являлся единственным христианским центром в Колхиде». (Правда, отмечено существенное влияние Питиунта). Однако в данном случае возникает у читателя вопрос: если есть общие черты у двух центров и храмы, относящиеся к близкому времени, почему же Питиунт был «единственным религиозным центром». Разве наличие культовых построек в Археополисе не свидетельствует о наличии еще одного раннего центра в регионе? Сходство двух центров прослежено и в том, что как крестовидная церковь в Питиунте появилась в результате трансформации более ранних построек, так и Археополисе базилика «Сорока Мучеников» перестроена в купольный храм. Далее, первые культовые сооружения в обоих случаях были небольшими однонефными церквами, характерными являлись также базилики. Но, считать отличительной (единственная, которая отмечена) то, что в Археополисе не существовало почитание святых, так как не выявлены храмы кладбищенские, вряд ли возможно. «Они (пока. - А. Р.) не найдены», как пишет Л. Г. Хрушкова (c. 345). Но ведь могут быть и «найдены». Те, кому удалось посетить Археополис, знают о чрезвычайно сложной современной топографии территории, где велись раскопки.

Завершает главу описание базилики у современного населенного пункта Вашнари (с. 345-352).

Значительная часть работы Л. Г. Хрушковой посвящена анализу декоративных мраморов (с. 354-395). Этот раздел сопровождают многочисленные иллюстрации, и он не требует освещения или анализа, поскольку практически всем, кто занимается историей христианства или же культовой архитектурой, хорошо знакома более ранняя специальная работа автора о скульптуре раннесредневековой Абхазии. ${ }^{11}$

Отличительной чертой, пока еще редкой для историко-архитектурных штудий, является обращение к такому сложному вопросу как «Обряды и литургические устройства» (глава 8). Этот раздел требует внимательного чтения каждым, кто посвятил себя изучению культовых сооружений вне зависимости от времени их строительства, и обсуждения со специалистами, кто в отличие от светских историков, лучше владеет информацией.

Безусловно, можно было бы дополнить список литературы, но в данном случае автор приводит «избранную библиографию», что снимает

трехнефная базилика, строительство которой датируется временем не позднее середины V в. (см.: Н. Ю. Ломоури, Основные результаты археологического изучения древнего Археополиса // Византиноведческие этюды (Тбилиси, 1991) 101).

${ }^{11}$ ХрушковА, Скульптура раннесредневековой Абхазии... 
упреки. ${ }^{12}$ Кроме того, любой из нас вправе упустить ту или иную работу, если он не «создает» историографического обзора.

В заключение «некоторых рассуждений» о новой монографии Л. Г. Хрушковой, которые, безусловно, не исчерпывают всего того, что рождалось по мере ее прочтения, отмечу наличие специальных приложений: глоссария, резюме (на английском языке), отражающего основное содержание каждой главы, указателя исторических лиц и имен современных исследователей памятников.

Обычно в аннотации ли, или в рецензии, принято писать, что новая книга является... Но мне хотелось бы завершить то, что было сказано выше, пожеланием новых открытий в собственном архиве Л. Г. Хрушковой и, следовательно, новых интересных для специалистов публикаций и поздравить ее выходом в свет накопленного в течение длительного изучения региона, сложных археологических исследований.

А. И. Романчук

\section{НОВЫЕ АИССЕРТАШИИ, ПОСВЯШЕННЫЕ ВИЗАНТИЙСКОЙ ПАТРИСТИКЕ}

\section{1. $\Delta$. И. МАКАРОВ, «ВизаНтийское обшество и человек в гомилиях св. Григория Паламы». Аиссертация на со- искание степени кандидата исторических наук (Ура^ь- ский Государственный университет; Екатеринбург, июнь 2003 г.; научный руководитель - М. А. Поляковская).}

Диссертационное исследование продолжает разработку темы, важность которой была хорошо осознана уже к середине XX века, однако, в настоящее время эта тема требует к себе нового обращения - как вследствие очень существенного, за последние 50 лет, углубления наших знаний о деятельности и учении самого св. Григория Паламы, так и вслед-

${ }^{12}$ Все же некоторые работы, ссылки на которые отсутствуют, хотелось бы Привести: П. ЗАКАРАЯ, В. ЛЕКВИНАДЗЕ, Г. ГВИНЧИДЗЕ, ОТчет работ Нокалакевской археологической экспедиции, проведенных в 1976-1977 гг. // Археологические экспедиции Государственного музея Грузии. Вып. 6 (1978) 85-87; М. М. ГунБА, Новые памятники Цебельдинской культуры (Тбилиси, 1978); Ломоури, Основные результаты... 96-109 (правда, Л. Г. Хрушкова приводит ряд работ данного автора на западноевропейских языках). Для понимания истории Эгисского (Лазского) царства интерес представляет и другая работа: Н. Ю. Ломоури, История Эгрисского царства: с возникновения до V в. н. э. (Тбилиси, 1968) (на груз. яз.). 